University of Nebraska - Lincoln

DigitalCommons@University of Nebraska - Lincoln

January 2000

\title{
Leg ornamentation and the efficacy of courtship display in four species of wolf spider (Araneae: Lycosidae)
}

\author{
Eileen Hebets \\ University of Nebraska - Lincoln, ehebets2@unl.edu \\ George W. Uetz \\ University of Cincinnati, Cincinnati, $\mathrm{OH}$
}

Follow this and additional works at: https://digitalcommons.unl.edu/bioscihebets

Part of the Behavior and Ethology Commons

Hebets, Eileen and Uetz, George W., "Leg ornamentation and the efficacy of courtship display in four species of wolf spider (Araneae: Lycosidae)" (2000). Eileen Hebets Publications. 17.

https://digitalcommons.unl.edu/bioscihebets/17

This Article is brought to you for free and open access by the Papers in the Biological Sciences at DigitalCommons@University of Nebraska - Lincoln. It has been accepted for inclusion in Eileen Hebets Publications by an authorized administrator of DigitalCommons@University of Nebraska - Lincoln. 
Published in Behavioral Ecology and Sociobiology 47 (2000), pp. 280-286.

Copyright (C) 2000 Springer-Verlag. Used by permission. http://www.springerlink.com/content/0340-5443

Submitted December 29, 1997; revised October 23, 1999; accepted December 13, 1999. Communicated for BES by M. A. Elgar.

\title{
Leg ornamentation and the efficacy of courtship display in four species of wolf spider (Araneae: Lycosidae)
}

\author{
Eileen A. Hebets and George W. Uetz \\ Department of Biology, University of Cincinnati, Cincinnati, OH 45221-00o6, USA
}

\begin{abstract}
This study used both correlative and experimental video playback methods to test the hypothesis that the secondary sexual traits of male wolf spiders act to increase the efficacy of visual courtship displays. Direct observations of courtship of several lycosid genera and a review of the literature revealed a significant association between ornamentation and visual courtship displays. This suggests that the ornamentation may be playing the role of amplifier for a visual display. To test this hypothesis, male courtship behaviors of four Schizocosa species were experimentally manipulated using video-imaging techniques. Females of species with non-visually displaying, nonornamented males (Schizocosa duplex and $S$. uetzi) did not increase in frequency of receptivity when tufts were added to conspecific males. In a species with a visual display and foreleg pigmentation (S. stridulans), the addition of foreleg tufts increased female receptivity. In a tufted species (S. crassipes), females tended to decrease their receptivity when male ornamentation was completely removed. In visually displaying species, ornamentation acts to increase female receptivity, supporting its role as an amplifier of a visual display.
\end{abstract}

Keywords: spiders, courtship efficacy, female choice, ornamentation, amplifier

\section{Introduction}

Although many scientists agree that sexual selection pressures lead to the evolution of elaborate male ornamentation, the mechanisms driving these ornate traits are still under debate. Among the many possible explanations for the evolution of ornaments (Andersson 1994), the idea of female choice has received the most support (Bischoff et al. 1985; Basolo 1990; Brooks and Caithness 1995; Ligon and Zwartjes 1995; Wiernasz 1995). Numerous studies have shown that females exhibit a preference among males, but the origin of these preferences remains unclear (Bateson 1983; Andersson 1994).

Females often choose males with more conspicuous traits (Andersson 1994). These traits may reduce the time it takes a female to locate a male (Darwin 1871), they may indicate high-quality males (Trivers 1972; Zahavi 1975), they may improve species recognition (Andersson 1994), or they may take advantage of a preexisting female sensory bias (West-Eberhard 1983; Ryan 1990; Endler 1992). Conspicuous male displays may also evolve through female choice if the display acts as an amplifier of a previously recognized difference in male quality (Hasson 1989, 1990). Amplifying displays may increase resolution of other cues without themselves being attractive.

Within the context of sexual selection through female choice, male secondary sexual traits are typically involved in courtship displays. The signaling involved in courtship plays a crucial role in the reproductive success and often survival of individuals. Courtship signals may not only include species recognition components, but must successfully elicit female receptivity. Displays used in sexual interactions are typically designed for detectability, and while there are several factors that can increase the detectability of a signal (Guilford and Stamp Dawkins 1991), there are associated costs (Ryan and Rand 1990; Endler 1991, 1993). As is common throughout all aspects of animal behavior, the signaler must maximize the efficacy of the signal while minimizing its associated costs. For some animal species, the costs associated with ineffective courtship signaling may be very high. In some spiders, for example, males often loose their lives to females during courtship attempts. The pressures placed on courtship signals in potentially cannibalistic animals such as spiders are thus thought to be extremely strong (Elgar 1992). 
The genus Schizocosa, within the wolf spider family Lycosidae, is an ideal system in which to study the role of male ornamentation in courtship displays. Courtship behavior in the family Lycosidae has been studied extensively (for a review see Stratton 1985). The signals that wolf spiders utilize consist mainly of visual, vibratory, and chemical forms. Within the genus Schizocosa, males possess a variety of foreleg morphologies ranging from the presence of brushes of black hair and/or pigmentation on their forelegs to males with forelegs without ornamentation. The courtship displays of males also vary, from species with extremely active leg-waving displays to species with stationary, vibration-based courtship.

Past studies have focused upon specific roles that ornamentation (specifically "tufts") may play in male courtship signaling, i.e., species recognition and female choice (McClintock and Uetz 1996; Scheffer et al. 1996). Tufts have been shown to increase the efficacy of visual courtship displays in Schizocosa ocreata (a tufted species), while it has been suggested that female $S$. rovneri (a non-ornamented species) may have a preexisting bias for active courtship displays and/or for the presence of decorative tufts (McClintock and Uetz 1996; Scheffer et al. 1996). This study expands the examination of foreleg morphologies to include two species with varying degrees of black pigmentation and no tufts on the forelegs, another "tufted" species, and another non-ornamented species. Using four additional species within the genus, each with varying degrees of male foreleg ornamentation and visual courtship display, we examined the role of ornamentation (specifically as an amplifier) in the context of visual courtship displays. We first explored the relationship between decoration and visual displays and then used video-imaging manipulations to modify male morphologies and test female receptivity.

If ornamentation acts in conjunction with visual displays to enhance communication, male foreleg ornamentation should be correlated with other visual courtship signals. Furthermore, if decorations act to enhance a visual display, then we would predict that in a species with a visual display, female receptivity should increase with artificially enhanced decorations or decrease when ornamentation is removed. There should be an ordering effect on female preference with respect to increased ornamentation. However, in a species with no visual display, the enhancement or addition of decorations should not affect female mate choice.

\section{Methods}

\section{Association of leg decoration and leg-waving displays}

We obtained data on the presence of leg ornamentation and leg-waving displays during courtship for 39 species of lycosids from eight genera (Table 1). Data for 11 species were obtained from the literature; the remaining species were observed directly from collections made in the summers of 1993-1994 from populations throughout Alabama, north- ern Florida, Kentucky, Louisiana, and Mississippi (USA). The numbers of individuals per species collected ranged from 1 to more than 20. The spiders were taken to the laboratory at the University of Mississippi, where they were housed individually in plastic containers in a controlled environment on a 12L:12D cycle. Two additional wolf spider species were collected from Hamilton Co., Ohio, and Cape May Co., New Jersey, in 1995. These spiders were brought back to the laboratory at the University of Cincinnati where they were housed in individual deli dishes under similar controlled conditions.

Females of each species were placed on a piece of filter paper the night prior to observation. At the time of observation, the filter paper was transferred to the $9.5-\mathrm{cm}$ transparent cylindrical observation arena. The conspecific male was introduced into the arena and courtship behavior was observed and often recorded using a Panasonic HD5000 video camera. Male courtship behavior was scored for leg-waving displays: any portion of the legs or palps that were raised, waved, or arched during courtship was scored as positive for a visual display. Visual displays typically involved leg movements not involved in normal walking or running. The preserved specimens of the males were then examined under a microscope to determine if there was any foreleg decoration- either black pigment present on the legs or tufts of black hairs. Literature describing the species and courtship displays of wolf spiders was also reviewed and analyzed.

A $\chi^{2}$-test was used to test the null hypothesis of independence of leg decorations and displays. Since the phylogenetic arrangement of the family Lycosidae is not know, it is not possible to use various recommended statistical procedures (e.g., Harvey and Pagel 1989). Instead, we conducted a second analysis in which we scored species in the same genus with the same character trait as a single value. This procedure accounted for the possibility that species within a genus that display the same character states may simply share a common ancestor and thus cannot be counted as independent data points.

\section{Video manipulation of male foreleg morphology}

Since it is impossible to add brushes of hairs to the forelegs of live male Schizocosa, or to delete pigmentation that is already present, video imaging was used to manipulate male foreleg morphology. Past research has shown the effectiveness of video playback experiments with spiders (Clark and Uetz 1990; McClintock and Uetz 1996).

\section{Species}

Four species of Schizocosa wolf spiders were used in this study.

(1) S. duplex Chamberlin males are non-ornamented and have a stationary, vibrational courtship display with no visual component.

(2) S. uetzi Stratton males have a "hint" of black pigmentation on the middle portion of tibia I (Stratton 1997a). The courtship display is stationary and mostly involves stridulation; however, males display a very slow foreleg arch and lift (Stratton 1997a).

(3) S. stridulans Stratton males have black pigmentation on their entire tibia I and distal portion of femur I. Males display with a rapid double foreleg tap along with stationary stridulatory courtship (Stratton 1997b).

(4) S. crassipes (Walckenaer) males have pigmentation on the femur, patella, and tibia of legs I along with "brushes" of black hairs on the tibia. The courtship of these males involves active walking about with extremely rapid extended leg-waving displays (description in Miller et al. 1998).

\section{Digitized courtship manipulations}

Male courtship sequences from each Schizocosa species were videotaped using a JVC GX-N8 camera and a Panasonic HRS-101 VHS video recorder. The camera distance from the live courting male was varied so that the image on the screen of a Sony Watchman was life size (dial calipers verified that the television image matched the average body 
length of that particular species). The videotape of the courting male was then digitized onto an AMIGA 2000HD computer using a Frame Grabber-Real Time Video Image Digitizer. We used 30 images for each second of courtship display on the videotape to ensure the inclusion of all behavioral displays within a sequence and allow real-time playbacks. An animation program (Deluxe Paint IV) was then used to manipulate the morphologies of males in each frame.

Because courtship behavior and duration differed among the four Schizocosa species, different durations of courtship displays were digitized for each species. The digitized courtship displays for $S$. duplex, S. uetzi, S. stridulans, and S. crassipes were 391, 1225, 601, and 1061 frames, respectively. Each of the digitized sequences was shown to females as continuous loops.

For each of the four species, three different video courtship sequences were created: (1) a no-ornamentation video: all ornamentation (pigment and brushes) were removed from species that normally possessed them; (2) a "pigmentation" video: black pigmentation was added to species normally lacking pigment and the brush was removed, leaving pigmentation as the only ornament in species that normally possessed "brushes", and (3) a "brushes" video: brushes of black hair were added to the forelegs of males that lacked natural "brushes." When brushes were added to species normally lacking them, pigmentation was, consequently, added as well (see Figure $3 \mathrm{D}$ leg drawing); thus, there was never a case of brushes without pigmentation. The resulting videos for each species included one unmanipulated video sequence and two sequences with altered foreleg morphologies.

Approximately 30 females of each species were randomly chosen for these trials, none of which had been used previously. The experimental arena consisted of a Sony Watchman micro screen television placed at one end of a clear plastic arena (Figure 1). A piece of paper was placed in front of the screen prior to each trial. Females were put in the arena on a piece of filter paper and were allowed to acclimate for exactly $2 \mathrm{~min}$. The trial began when the barrier in front of the screen was removed and the female was exposed to a video playback of a previously digitized courtship sequence loop. Trials lasted $10 \mathrm{~min}$ and the female was scored for receptivity (i.e., a slow turn or settle; see McClintock and Uetz 1996; Stratton 1997b; Hebets and Uetz 1999). Each female was used once only. A log-likelihood ratio test ( $G$-test) was used to test the null hypothesis that female receptivity was independent of stimulus shown. If female receptivity was found to be dependent upon the stimulus shown, a Fisher exact test was done on pairwise comparisons.

To test the predictions that female responses should be ordered according to increased ornamentation, we used the Jonckheere test for ordered alternatives (Siegel and Castellan 1988). Since this prediction only holds true for species in which a visual display is involved in courtship, S. duplex was not included in this analysis.

Table 1 . An examination of wolf spiders for the presence/absence of ornamentation and leg-waving displays

\begin{tabular}{|c|c|c|c|c|}
\hline Genus & Species & Ornament & Leg-waving & Source \\
\hline \multirow[t]{2}{*}{ Arctosa } & littoralis & - & Yes & Present study \\
\hline & sanctaerosae & Yes & Yes & Present study \\
\hline \multirow[t]{2}{*}{ Alopecosa } & accentuata & Yes & Yes & Cordes 1988 \\
\hline & barbipes & Yes & Yes & Cordes 1988 \\
\hline Geolycosa & turricola & Yes & Yes & Present study \\
\hline Gladicosa & bellamyi & Yes & Yes & Present study \\
\hline \multirow{3}{*}{ Lycosa } & georgicola & Yes & Yes & Present study \\
\hline & lenta sp. "a" & - & - & Present study \\
\hline & lenta sp. "b" & - & Yes & Present study \\
\hline \multirow[t]{7}{*}{ Pardosa } & amentata & Yes & Yes & Vlijm and Dijkstra 1966; Hollander 1970; Cordes 1988 \\
\hline & hortensis & Yes & Yes & Vlijm and Dijkstra 1966; Locket and Millidge 1975 \\
\hline & littoralis & Yes & Yes & Present study \\
\hline & prativaga & - & - & Hollander et al. 1973 \\
\hline & proxima & - & Yes & Hollander and Dijkstra 1974 \\
\hline & pullata & - & - & Hollander et al. 1973 \\
\hline & saturatior & - & Yes & Vlijm et al. 1970; Cordes 1988 \\
\hline \multirow[t]{2}{*}{ Rabidosa } & hentzi & - & - & Present study \\
\hline & rabida & Yes & Yes & Present study \\
\hline \multirow[t]{7}{*}{ Schizocosa } & aulonia & Yes & Yes & Present study \\
\hline & avida & - & Yes & Present study \\
\hline & crassipes & Yes & Yes & Present study \\
\hline & duplex & - & - & Present study \\
\hline & floridana & - & Yes & Present study \\
\hline & mccooki & - & - & Present study \\
\hline & ocreata & Yes & Yes & Present study \\
\hline
\end{tabular}




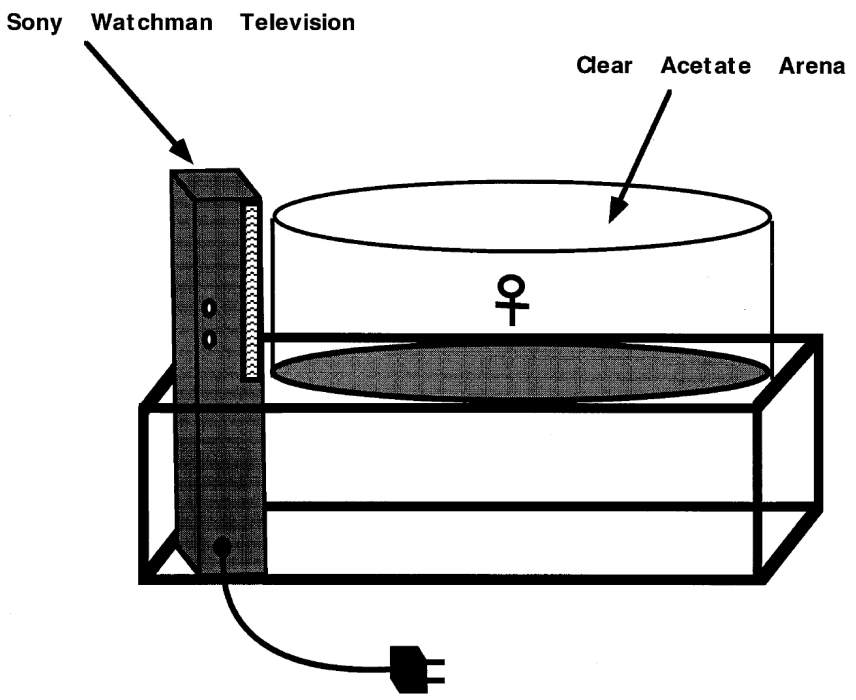

Figure 1. Video playback arena

\section{Results}

\section{Correlation between leg decoration and visual leg-waving displays}

There was interspecific variation in the presence of leg decorations and visual displays (Table 1 ). The Yates-corrected $\chi^{2} 2 \times 2$ contingency test showed that for all 39 species, the presence of leg decorations and visual displays were not independent $\left(\chi^{2}=17.4, P<0.00001\right.$; Figure 2A). Our analysis, which counted species in the same genus with the same character traits as a single value, yielded a total of 16 data points. A Fisher exact test revealed that the presence of leg decorations and visual displays were not independent $(P<0.02$; Figure $2 \mathrm{~B})$.

\section{Female receptivity to manipulated male morphologies}

S. duplex females showed no receptivity to video stimuli and, thus, female receptivity was independent of stimulus shown ( $G=0$; Figure $3 \mathrm{~A}$ ). Only a few $S$. uetzi females responded to video stimuli, and adding brushes to male forelegs did not affect female receptivity, nor did the removal of pigment. Female receptivity was thus independent of the stimulus shown $(G=0.934, P=0.627$; Figure $3 \mathrm{~B}$ ). Although there were definite trends within some of the species with respect to female receptivity to video stimuli, only one species showed statistically significant differences. $S$. stridulans female receptivity responses were dependent upon the video stimulus shown $(G=6.9763, P=0.037$; Figure $3 \mathrm{C})$. Females preferred males with brushes added over males with pigment removed $(P=0.03)$. With a Bonferroni correction for the overall experimentwise error rate, this trend is significant (pairwise, $P=0.017$ ). In $S$. crassipes, females appeared less receptive to males when ornamentation was removed from the forelegs. However, because the sample

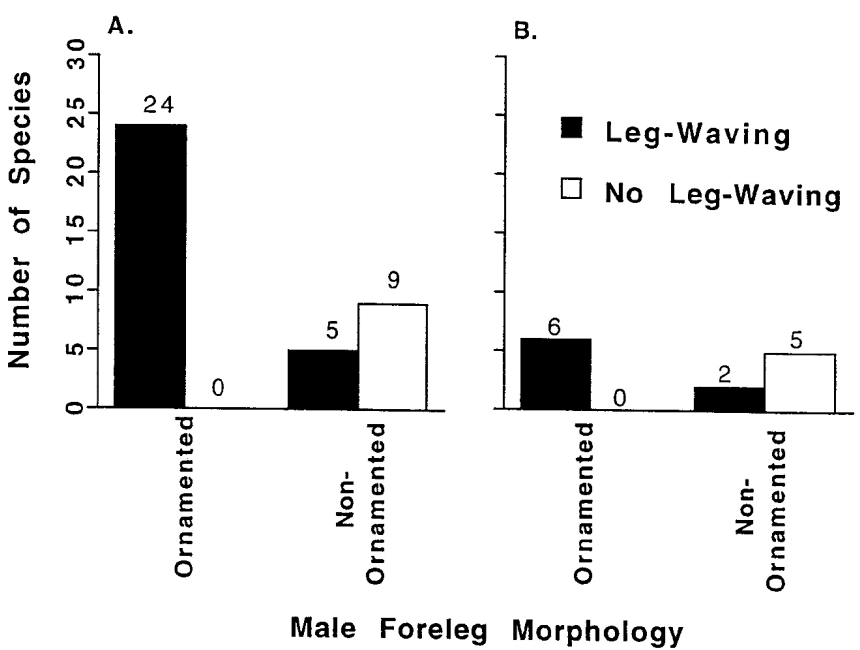

Figure 2, A, B. The frequency of co-occurrence of leg ornamentation and leg-waving displays in the family Lycosidae. A) Data from all species. B) Data in which species in the same genus with the same character traits are treated as a single value

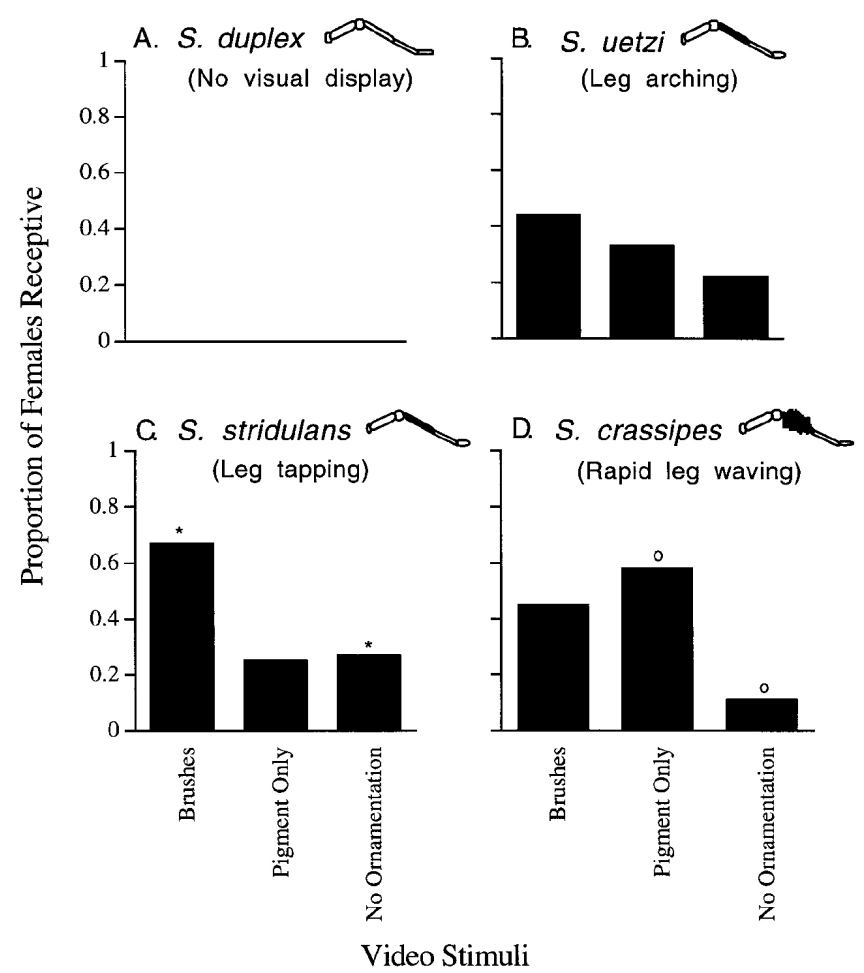

Figure 3, A-D. Female Schizocosa responses to video playback (* significant differences at $P<0.05 ;^{\circ}$ marginally significant differences at $P=0.07$ ).

A) $S$. duplex (brushes $n=9$, pigment only $n=9$, no ornament $n=9$ ).

B) $S$. uetzi (brushes $n=9$, pigment only $n=9$, no ornament $n=9$ ).

C) $S$. stridulans (brushes $n=12$, pigment only $n=12$, no ornament $n=11$ ).

D) $S$. crassipes (brushes $n=11$, pigment only $n=12$, no ornament $n=9$ )

size was small ( $n=12)$, we cannot rule out independence $(G=5.14, P=0.076$; Figure 3D).

The Jonckheere test for ordered alternatives indicated that females of $S$. uetzi, $S$. stridulans, and $S$. crassipes all showed a significant increase in receptivity related to an increase in male foreleg ornamentation $(J=24, P=0.01)$. 


\section{Discussion}

Male leg ornamentation within the wolf spider family Lycosidae is strongly associated with the presence of legwaving displays during courtship. All ornamented species examined possess some type of visual courtship display; we found no examples of species possessing ornamentation that lacked leg waving. However, seven species possessed an active display but were not ornamented, possibly suggesting that visual displays evolved first. A good phylogenetic history is not available for any of these spider genera or for the family itself and, thus, it is difficult to discuss the evolutionary history of courtship behavior in relation to male morphology. Better knowledge of the relationships within and between these genera would enable direct testing of the hypothesis that active leg-waving displays evolved first and ornamentation followed, playing the role of an amplifier of courtship signals in lineages with visual displays.

Our hypothesis was that ornamentation has evolved in this system to enhance visual courtship signals. According to Hasson (1991), females should not respond to the presence of an "amplifier" unless it is enhancing a previously desired male quality, such as display rate. S. duplex males, which lack a leg-waving display, do not possess a visual quality indicator (such as rate of display) which ornamentation might amplify. As predicted, females of this species did not respond to any male visual cue. If novel ornamentation was simply more attractive to a female in and of itself, then females should have increased their receptivity to males with added brushes. Although these data follow Hasson's predictions, there are other possible explanations that cannot be ruled out, e.g., phylogenetic constraints on the sensory system of female $S$. duplex.

In the two species with active leg-waving displays, $S$. crassipes and $S$. stridulans, the results of the playback trials also lend support to the amplifier hypothesis. Although the overall difference was only marginally significant $(P=0.07)$, there was a definite trend within $S$. crassipes females to decrease receptivity from a decorated or pigmented male to a male without any ornamentation. In $S$. stridulans, females preferred males with brushes added over non-ornamented males.

Thus, in species with active visual displays, but without ornamentation, an increase in male ornamentation resulted in an increase in female receptivity. Results from $S$. stridulans females do not fit the predictions perfectly, however, since unmanipulated males were not preferred over non-ornamented males. However, the sample sizes once again were small and the female preference differences between these two treatments were negligible (i.e., 0.02 difference in proportions of receptive females). Overall, our results indicate that an increase in female receptivity is directly related to an increase in the degree to which males display visually.
Female $S$. uetzi did not respond differently to manipulated video stimuli, even when brushes were added. This lack of a significant response may be explained by the absence of an obvious quality indicator for females to assess. The courtship display of this species does not involve any quick tapping movements or leg-waving displays; it simply involves a male slowly arching the foreleg and then lowering it again. Although it is possible that the speed of both the arching and the leg raise could potentially act as quality indicators, these subtle displays may be more difficult for a female to assess. A more powerful analysis is needed to further address these issues.

These findings do not at first appear in accordance with previous studies by McClintock and Uetz (1996). They found that female $S$. rovneri were more receptive to conspecific males with brushes added than to control conspecifics, suggesting that females prefer decorative tufts even in the absence of any leg-waving display. However, female $S$. rovneri also responded to male $S$. ocreata with or without tufts, suggesting a pre-existing bias for active, visual courtship displays. Although S. rovneri males do not exhibit leg-waving during courtship, they do exhibit a vigorous abdomen bounce. When the males bounce, their bodies come down with great force on the substratum and their legs are often lifted; much of the body vibrates immediately after each bounce. As a result, although there are no leg-waving displays, active movement occurs during courtship. Any amplification of this movement should be preferred by females and this may explain why female $S$. rovneri prefer conspecific tufted males over controls.

If, as we propose, ornamentation amplifies a visual display, then females must be assessing something in the visual display. They may, for example, be interested in the rate of display. In several different animal species, factors most important in mate choice for females have less to do with morphology (e.g., size or coloration) than with courtship rate (Collins 1995; Karino 1995; Wagner and Sullivan 1995; Wagner et al. 1995). In a study involving another species of wolf spider (Hygrolycosa rubrofasciata), Parri et al. (1997) were able to show that rate and volume play an important role in male drumming during courtship. Females responded more quickly to males with higher drumming rates and volumes (Parri et al. 1997).

The importance of display rate has been shown for a variety of animal species and a variety of signaling modes, including the vibratory components of wolf spider courtship. A more recent study of male-female pairings in both $S$. rovneri and $S$. ocreata demonstrated that males that actually mated had more active courtship (bounces per minute and taps per minute, respectively) than those that did not (K. Delaney and G. W. Uetz, unpublished data). It seems likely that rate is important in visual components of wolf spider courtship. Future studies, involving more species, that focus upon the effect 
that different rates of leg waving may have on female choice could lend more support to the notion that ornamentation acts as an amplifier.

Our results suggest that a correlation exists between male foreleg ornamentation and visual leg-waving displays in wolf spiders. Thus, it seems reasonable to assume that in all species with these traits, females are using visual courtship components to assess males. However, Scheffer et al. (1996) previously showed that not all species may have this female visual bias. Hebets and Uetz (1999) found that among six species of Schizocosa females, three exhibited a vibrational bias during courtship assessment. The proportion of females receptive to isolated visual cues of a courting conspecific male increases in more ornamented, visually courting species (Hebets and Uetz 1999). The differences in female communication biases may help explain the variation with respect to male foreleg morphology and courtship communication seen in this genus.

This study controlled for conspecific male courtship display while experimentally manipulating morphology. Future studies should directly address issues of female receptivity in response to varying degrees of visual courtship displays. By experimentally altering both morphology and behavior in opposite directions, we may be able to gain insight into the relative importance of both ornamental and visual cues used during courtship communication.

\section{Acknowledgments}

This research satisfied part of the requirements for the Master of Science degree at the University of Cincinnati. We would like to thank B. Jayne and G. Stratton for their insights and helpful criticisms on this manuscript. The species collections were aided by P. Miller, G. Stratton, and S. Redella. Other thanks go out to G. Miller, M. Persons, A. DeLay, M. DeLay, K. Pedley, D. Kroeger, L. Smith, S. Smith, K. Delaney, A. Pruden, D. Schenk, and especially S. Redella. Also, E. Dyreson helped out greatly with the statistics. This research was supported by a NSF Grant IBN-9414239 (to G. Uetz), a grant from the Sigma Xi Society, an Arachnological Society Grant, two Harry L. Wieman Summer Research Fellowships from the Department of Biological Sciences at the University of Cincinnati, and the Arachnological Research Fund of the University of Cincinnati.

\section{References}

Andersson M (1994) Sexual selection. Princeton University Press, Princeton, NJ

Basolo AL (1990) Female preference for male sword length in the green swordtail, Xiphophorus helleri (Pisces: Poeciliidae). Anim Behav 40:332-338

Bateson P (1983) Mate choice. Cambridge, Cambridge University Press, UK
Bischoff RJ, Gould JL, Rubenstein DI (1985) Tail size and female choice in the guppy (Poecilia reticulata). Behav Ecol Sociobiol 17:253-255

Brooks R, Caithness N (1995) Female choice in a feral guppy population: are there multiple cues? Anim Behav 50:301-307

Clark DL, Uetz GW (1990) Video image recognition by the jumping spider Maevia inclemens (Araneae: Salticidae). Anim Behav 40:884-890

Collins SA (1995) The effect of recent experience on female choice in zebra finches. Anim Behav 49:479-486

Cordes D (1988) Beobachtungen zum Sexualverhalten ausgewahlter Wolfspinnenarten (Araneae, Lycosidae) zur taxonomischen Kennzeichnung von Ethospezies. M.Sc. thesis, Friederich-Alexander-Universität Erlangen-Nürnberg

Darwin C (1871) The descent of man and selection in relation to sex, 1st edn. Murray, London

Elgar MA (1992) Sexual cannibalism in spiders and other invertebrates. In: Elgar MA, Crespi BJ (eds) Cannibalism: ecology and evolution among diverse taxa. Oxford University Press, Oxford, pp 129-156

Endler JA (1991) Variation in the appearance of guppy color patterns to guppies and their predators under different visual conditions. Vision Res 31:587-608

Endler JA (1992) Sensory drive: does sensory biology bias or constrain the direction of evolution? Am Nat 139:S1-S3

Endler JA (1993) Some general comments on the evolution and design of animal communication systems. Phil Trans $R$ Soc Lond B 340:215-225

Guilford T, Stamp Dawkins M (1991) Receiver psychology and the evolution of animal signals. Anim Behav 42:1-14

Harvey PH, Pagel M (1989) The comparative method in evolutionary biology. Oxford, Oxford University Press

Hasson O (1989) Amplifiers and the handicap principle in sexual selection: a different emphasis. Proc R Soc Lond B 235: 234-406

Hasson O (1990) The role of amplifiers in sexual selection: An integration of the amplifying and the Fisherian mechanisms. Evol Ecol 4:277-289.

Hasson O (1991) Sexual displays as amplifiers: practical examples with an emphasis on feather decorations. Behav Ecol 2: 189-197

Hebets EA, Uetz GW (1999) Female responses to isolated signals from multi-modal male courtship displays in the wolf spider genus Schizocosa (Lycosidae:Araneae). Anim Behav 57:865- 872

Hollander JD (1970) Morphological variation in Pardosa prativaga L. Kock, 1870, P. prativaga var. fulvipes Collett, 1987 and $P$. pullata Clerk, 1757. Tijdschr Entomol 113: 273-290

Hollander J, Dijkstra H (1974) Pardosa vljimi sp. nov. a new ethospecies sibling Pardosa proxima (C.L. Kock, 1848), from France, with description of courtship display (Araneae, Lycosidae). Beaufortia 289:57-65

Hollander JD, Dijkstra J, Alleman H, Vlijm L (1973) Courtship behaviour as a species barrier in the Pardosa pullata group (Araneae: Lycosidae). Tjidschr Entomol 116:1-22 
Karino K (1995) Male-male competition and female mate choice through courtship display in the territorial damselfish Stegastes nigricans. Ethology 100:126-138

Ligon JD, Zwartjes PW (1995) Ornate plumage of male red jungle fowl does not influence mate choice by females. Anim Behav 49:117-125

Locket GH, Millidge AF (1975) British spiders, vol 1 London, Ray Society

McClintock WJ, Uetz GW (1996) Visual cues in species recognition and female choice in two Schizocosa wolf spiders (Araneae: Lycosidae). Anim Behav 52:167-181

Miller GL, Stratton GE, Miller PR, Hebets E (1998) Geographical variation in male courtship behaviour and sexual isolation in wolf spiders of the genus Schizocosa. Anim Behav 56:937- 951

Parri S, Alatalo RV, Kotiaho J, Mappes J (1997) Female choice for male drumming in the wolf spider Hygrolycosa rubrofasciata. Anim Behav 53:305-312

Ryan MJ (1990) Signals, species and sexual selection. Am Sci 78: $46-52$

Ryan MJ, Rand AS (1990) The sensory bias of sexual selection for complex calls in the tungara frog, Physalaemus pustulosus. Nature 343:66-67

Scheffer SJ, Uetz GW, Stratton GE (1996) Sexual selection, male morphology, and the efficacy of courtship signaling in two wolf spiders (Araneae: Lycosidae). Behav Ecol Sociobiol 38: 7-23

Siegel S, Castellan NJ (1988) Nonparametric statistics for the behavioral sciences. McGraw-Hill, New York

Stratton GE (1985) Behavioral studies of wolf spiders: a review of recent research. Rev Arachnol 6:57-70
Stratton GE (1997a) A new species of Schizocosa from the southeastern USA (Araneae, Lycosidae). $J$ Arachnol 25:84-92

Stratton GE (1997b) Investigation of species divergence and reproductive isolation of Schizocosa stridulans (Araneae: Lycosidae) from Illinois. Bull Br Arachnol Soc 10:313-321

Trivers RL (1972) Parental investment and sexual selection. In: Campbell B (ed) Sexual selection and the descent of man. Chapman \& Hall London, pp 136-179

Vlijm L, Dijkstra H (1966) Comparative research of the courtship behavior in the genus Pardosa (Arachnida: Araneae). II. Some remarks about the courtship behavior in Pardosa pullata (Clerk). Bull Mus Nat Hist Nat Paris 41:112-116

Vlijm L, Hollander JD, Wendelaar-bonga SE (1970) Locomotory activity and sexual display in Pardosa amentat (Cl.) (Lycosidae, Araneae). Neth J Zool 29:475-484

Wagner WE Jr, Sullivan BK (1995) Sexual selection in the Gulf Coast toad, Bufo valliceps: female choice based on variable characters. Anim Behav 49:305-319

Wagner WE Jr, Murray A, Cade WH (1995) Phenotypic variation in the mating preferences of female field crickets Gryllus integer. Anim Behav 49:1269-1281

West-Eberhard MJ (1983) Sexual selection, social competition, and speciation. $Q$ Rev Biol 58:155-183

Wiernasz DC (1995) Male choice on the basis of female melanin pattern in Pieris butterflies. Anim Behav 49:45-51

Zahavi A (1975) Mate selection - a selection for a handicap. $J$ Theor Biol 53:205-214 